\title{
Movimentos sociais e subjetivação política: anotações sobre sociabilidade política brasileira recente
}

\author{
Social movements and political subjectivity: \\ notes on recent Brazilian political sociability
}

\author{
Joana da Silva Barros*
}

\begin{abstract}
Resumo - A reflexão sobre os mecanismos de participação popular e de democratização da vida política brasileira está umbilicalmente ligada ao debate sobre os sujeitos políticos, sua constituição no âmbito da formação social brasileira e sobre as disputas políticas em torno da concepção de país que daí emerge. Neste artigo, busco articular estas duas dimensões analíticas, a partir da leitura do passado recente e da experiência de democratização no país, desde os anos 1980. Por outro lado, procuro abrir uma perspectiva de compreensão das formas de nomeação dos "de baixo", ou seja, das camadas populares e seus significados para a compreensão da formação social e da sociabilidade política brasileira.

Palavras-chave: movimentos sociais; participação popular; democracia; sociabilidade política brasileira.
\end{abstract}

\begin{abstract}
The reflection on the mechanisms of popular participation and democratization of Brazilian political life is inextricably connected to the debate about political subjects, their constitution within the Brazilian society and the political disputes around the conception of nation that emerges therefrom. This article puts together these two analytical dimensions, from an analysis of the recent past and the experience of democratization in the country, since the 1980s, and on the other hand, opening a perspective of understanding the ways of naming of the working classes and their meanings for understanding the social formation of Brazilian politics and its sociability.

Keywords: social movements; people's participation; democracy; Brazilian political sociability.
\end{abstract}

\footnotetext{
*Arquiteta e urbanista. Doutora em sociologia pela Faculdade de Filosofia, Letras e Ciências Humanas da Universidade de São Paulo (USP). Assessora nacional da FASE - Solidariedade e Educação. Correspondência: Rua Uberaba, n. 3, apto.603, Grajaú, Rio de Janeiro (RJ). E-mail:<joana.jsb@gmail.com.>.
} 


\section{Participação popular: uma questão e seu campo de discussão}

As relações entre cidade e política, ao longo da década de 1990, alteraram-se profundamente. Este parece ser um ponto de partida comum, na produção sociológica desde a metade dos anos 1990, a várias e distintas formas de apreensão, leitura e análise da realidade brasileira atual. Sobretudo das formas de compreensão da vida urbana e da participação política que se seguiu à chamada redemocratização brasileira, a partir de 1985.

A problematização da vida pública brasileira e seus impasses encontrou, nos anos 1980, centralidade no aparecimento de novos sujeitos políticos ou "novos personagens", usando expressão célebre cunhada por Eder Sader (1988), que serviu de inspiração para uma profícua discussão nos anos 1980 e 1990. Essas leituras do cenário brasileiro, ao mesmo tempo em que analisavam a cena pública da época, "acertavam as contas" com a história da formação brasileira, relendo e problematizando as figurações e entendimento da formação, do papel e das maneiras de aparecimento e atuação políticos das classes populares. Estes eram lidos até ali na chave da incompletude e da impossibilidade de acesso à cidadania, aos direitos sociais e à vida pública; tal visão foi problematizada por Paoli (1987), Paoli e Sader (1986), Sader (1988) e Telles (1999).

O que então se colocavam em questão eram os próprios vínculos entre cidade e política, iluminando a experiência política dos trabalhadores para além dos seus locais de trabalho, privilegiando a leitura dos seus locais de sociabilidade e suas formas de vida. Assim, no campo da teoria sociológica, ultrapassava-se a concepção estrita dos trabalhadores como meros operários, rejeitando a herança ortodoxa do marxismo althusseriano. Por outro lado, no campo das práticas sociais, viu-se um "arejamento" das formas de organização dos trabalhadores, fundado na crítica à trajetória dos partidos de esquerda centralizados e na procura de uma organização mais horizontal dos "de baixo", na expressão de Florestan Fernandes.

Nesse encontro entre as práticas populares e as novas interpretações acadêmicas de sua trajetória, situa-se o nascimento de experiências de democratização dos espaços de decisão política sobre a coisa pública. Ali mesmo se refaziam as relações entre cidade e política, tanto nos marcos da literatura quanto da própria experiência concreta dos movimentos sociais.

Neste sentido, a Constituinte de 1988 é um momento importante, uma vez que representou um novo marco jurídico que, em alguma medida, exprimia os anseios e expectativas de uma sociedade democrática, instituindo mecanismos e formas de participação popular e social na vida política do Brasil, recém-saído da Ditadura Militar, para além da democracia representativa. A importância da Constituinte também reside no fato de que, a partir deste novo arcabouço jurídico-legal, formas de participação popular foram reconhecidas como justas, ao menos formalmente e abriram, então, caminho para afirmar-se como uma prática de gestão compartilhada 


\section{hevistg all paUtg}

\} MOVIMENTOS SOCIAIS E SUBJETIVAÇÃO POLÍTICA - BARROS, J. S. \}

das políticas públicas, dos programas sociais e dos recursos concernidos nessa disputa. A inscrição desses mecanismos no corpo da lei constitucional é uma importante vitória dos movimentos sociais, sindicais e populares e, sendo resultado de lutas, com avanços e derrotas desses segmentos, serviu como referência na disputa pelos rumos da democratização brasileira ao longo dos anos 1990.

A consolidação dessas novas formas de participação popular câmaras setoriais, fóruns de negociação, conselhos gestores de políticas públicas - na vida política brasileira, entretanto, ocorreu concomitantemente às transformações pelas quais passou a economia mundial e a forma específica como o capitalismo se reorganizou (e ainda o faz) na periferia do mundo e no Brasil, sob a insígnia de globalização ou do neoliberalismo. Essa concomitância teve impacto não desprezível sobre as formas de organização da vida política do país e, especialmente, sobre as possibilidades de realização das promessas de democratização e emancipação concernidas nestas.

É possível perceber os impactos dessas transformações em diversas dimensões da vida social, seja na organização da produção (nos locais de trabalho e na organização sindical), seja na cidade (na gestão urbana e nas suas formas de regulação, ou na falta dela), seja no aparecimento e consolidação de novos espaços de discussão de temas e questões até então postos à margem da vida pública brasileira.

Olhados em perspectiva, as novas formas de participação apresentam-se como uma experiência bifronte. Resultado do acúmulo popular que emergiu com força nos anos 1980, essas formas de democratização do Estado e da vida política brasileira, em certa medida, herdaram nos anos 1990 as "energias utópicas" de construção dos mecanismos de partilha de poder entre Estado e sociedade da década anterior. Contudo, essa experiência se realiza sobre um solo movediço de transformação da economia brasileira e também da vida política e social.

O nó naquele período (que se estende e transforma até os anos que se seguem) parece ser justamente a constituição de espaços de debate e deliberação pública - esperava-se a consolidação de uma experiência democrática -, num cenário de intensa privatização da vida e de redução de horizontes públicos. Parece um contrassenso, mas não é: tudo se passa como se a política fosse desnecessária, ou, nas palavras de Francisco de Oliveira (1999, p. 57), constitui-se "uma experiência subjetiva de desnecessidade, aparente, do público", que a bem da verdade, encobre o movimento real de constituição de formas, naquele momento necessárias à reprodução do capital, com o embaralhamento entre Estado e mercado, que deslegitima a fala dissensual e anula a possibilidade de conflito (RANCIÈRE, 1996).

A produção acadêmica sobre os conselhos setoriais e as práticas de participação popular na administração pública, notadamente os orça- 


\section{Revigta all paעtg}

\} MOVIMENTOS SOCIAIS E SUBJETIVAÇÃO POLÍTICA - BARROS, J. S. \}

mentos participativos, fornecem algumas pistas importantes sobre os eixos de interrogação privilegiados nesse processo. Além disso, armam uma constelação de temas e questões que foram postos em debate ao longo dos anos 1990. Sem dúvida alguma, a relação Estado/sociedade civil parece ser o centro articulador e irradiador dos questionamentos desses estudos, problematizada sob a ótica da cultura política (DAGNINO, 1994; BAIERLE, 2000).

A compreensão dos anos 1990 e das novas relações entre Estado e sociedade civil estava, em certa medida, impregnada de esperanças e da aposta de que, desse "encontro" (DAGNINO, 1994), a questão democrática no Brasil fosse problematizada de maneira diferente. Da mesma forma, esperava-se que os processos reais de questionamento das formas autoritárias presentes no aparelho estatal, na sociabilidade e nas práticas políticas possibilitassem a abertura de espaços à participação societária na gestão pública. Além disso, que eles fomentassem a constituição de espaços públicos de reconhecimento das demandas legítimas que partiam da sociedade civil organizada, consolidando uma nova cultura política e uma cidadania renovada.

Essas análises (e também as apostas) não se furtaram à crítica dos limites e das contradições reais dos processos de implantação de orçamentos participativos, de conselhos gestores e dos mecanismos de controle social sobre a máquina pública, do aparecimento e do papel das ONGs e sua relação com os movimentos sociais, da instituição e institucionalização dos chamados "espaços de encontro" entre sociedade e Estado, dos quais supostamente emergiriam novas práticas democráticas, a partir de um novo aprendizado da democracia.

O cenário político dos anos 1990, que adentra os anos 2000, ou uma das faces dos "anos bifrontes", agrega um elemento importante ao debate sobre a questão democrática brasileira: o desmanche neoliberal (SCHWARZ, 1999), momento do encolhimento das políticas públicas universais e da regulação estatal como elemento fundamental para manutenção de uma ordem social, na qual ainda fosse possível a dimensão de disputa pública e política.

A discussão sobre os impasses dos movimentos sociais e sindicais, as maneiras de desconstrução de sua representação política e as consequências para a vida pública no Brasil comparecem, de maneira pouco expressiva, no viés teórico de problematização que se debruça sobre as formas participativas de gestão pública - o que pode indicar já uma questão em aberto. Um exemplo na contramão dessa tendência na literatura é o artigo "Sociedade civil, espaços públicos e a construção democrática no Brasil: limites e possibilidades", no qual Evelina Dagnino problematiza as experiências de conselhos e espaços públicos para gestão participativa e da atuação das ONGs em nome dos movimentos sociais. A autora chama atenção para os impasses com os quais se deparam os "atores" envolvidos: 


\section{Aevistg all paUtg}

\} MOVIMENTOS SOCIAIS E SUBJETIVAÇÃO POLÍTICA - BARROS, J. S. \}

Sua centralidade [da complementaridade instrumental entre propósitos do Estado e da sociedade civil] se relaciona com o fato de que ela tem se construído nos últimos anos como uma estratégia do Estado para a implantação do ajuste neoliberal que exige o encolhimento das suas responsabilidades sociais. Nesse sentido, ela faz parte de um campo marcado por uma confluência perversa entre um projeto participatório, construído, a partir dos anos 80, ao redor da extensão da cidadania e do aprofundamento da democracia, e o projeto de um Estado mínimo se que isenta progressivamente do seu papel de garantidor de direitos. (2002, p. 288-289 - grifos no original).

Por um lado, essa produção, que se debruçou sobre a experiência dos movimentos sociais e dos frutos nascidos do questionamento sobre as formas de sociabilidade política brasileira, colocava acento e armava a discussão, partindo da noção de direitos sociais e do aprendizado político que a sua reivindicação e as formas de organização comunitárias fomentavam. No entanto, é preciso sublinhar que, naquele mesmo período, teve lugar no Brasil o que podemos chamar de acantonamento dos movimentos social e sindical, cujo paradigma de silenciamento foi a greve dos petroleiros em 1995 (MIAGUSKO, 2001).

É importante notar, também naquele período, a consolidação do Movimento dos Trabalhadores Sem-Terra (MST), no cenário brasileiro, como importante expressão dos trabalhadores rurais, cuja pauta, partindo de demandas específicas, procurou extrapolar o circuito das questões da produção agrícola. De certa maneira, o MST constituiu-se como polo de atração e tensionamento da esquerda brasileira e latino-americana - e, portanto, também dos movimentos sociais urbanos -, justamente no período de crise e fragmentação desse campo político. Outro ponto de destaque e de polarização do debate, com pouca projeção nesses conflitos, diz respeito à configuração das causas ambientais e de povos tradicionais e/ou originários como questão política.

A produção acadêmica sobre as transformações econômicas e políticas que ocorreram durante os anos 1990 e seu impacto no Brasil, sobre as disputas pelo fundo público, assim como a perda da capacidade de regulação do Estado, apontou como resultado desse processo a "desnecessidade do público" e da política (OLIVEIRA, 1999). Além disso, trouxe ao debate a interrogação sobre as possibilidades e os limites desses novos "encontros democratizantes", uma vez que o solo onde essas experiências se enraizavam não constituía mais a possibilidade de disputa pública e, em última instância, da própria política. É curioso ver que justamente a gestão das precariedades e a pobreza crescente no Brasil nos anos 1990 - o ponto cego na literatura sobre os movimentos sociais aparece aqui como o ele-mento que possibilita um questionamento mais profundo sobre as virtuosidades aparentemente presentes nesses "encontros" entre sociedade civil e Estado. 


\section{Revigta all paעtg}

\} MOVIMENTOS SOCIAIS E SUBJETIVAÇÃO POLÍTICA - BARROS, J. S. \}

Colocando em outros termos, a constatação de que é nesse solo histórico de profunda mudança na base econômica brasileira que se funda a experiência de gestão participativa e de uma prática política pretensamente democrática. Isto nos exige questionar se esses mesmos mecanismos nos quais se apostou não acabaram por funcionar como seu avesso: mostrandose não como instrumentos políticos inovadores, mas como meios de gestão de precariedades da vida dos trabalhadores e dos mais pobres.

Se o acento da produção acadêmica sobre os movimentos sociais estava na ideia de que esses novos "encontros" pudessem (e puderam de alguma maneira) servir como uma espécie de "pedagogia" da democracia e dos seus jogos de procedimentos, parece que, em certa medida, esse aprendizado corroeu a possibilidade de aparecimento de conflito e de questionamento da herança autoritária que queríamos superar. O procedimento anulou o conflito. Resiste, como enigma não decifrado, a gestão dos recursos públicos para a introdução e ampliação das políticas públicas, sobretudo aquelas "definidas" pelos orçamentos participativos e conselhos setoriais, bem como os limites ali encontrados.

Restou trazer à luz esse movimento de democratização e participação popular, que não se coloca nem apesar de, tampouco contra esse cenário de impossibilidade da política; mas justamente neste cenário, entre estas duas polaridades: de um lado, a aposta na disputa e na introdução de uma nova cultura política democrática; de outro, como que expondo e cobrando os limites dessa experiência, a disputa pelos fundos públicos e sua capacidade de publicização do debate sobre o financiamento estatal e sua dimensão política.

Parte da tradição do pensamento brasileiro entendeu São Paulo (ou aquilo que um dia se afirmou como a imagem que o estado industrializado representava) como síntese imperfeita, é verdade, e como indutor da modernização brasileira. As clivagens arcaico-moderno e urbano-rural compreenderam as dificuldades (ou especificidades, se lidas em outra perspectiva) de modernização e de democratização brasileiras na chave explicativa da falta e da incompletude. Tal formulação ancorava-se na leitura do processo de desenvolvimento econômico e transformação da estrutura e da sociabilidade políticas, através da superação do passado brasileiro, nomeado como colonial, escravista, rural, atrasado, arcaico e marcado pela violência privada no mundo público. Todos esses atributos deveriam ser superados pela modernidade vindoura, assim como, extrapolando o argumento, supunha-se que deveriam ser superados os grupos e/ou camadas sociais que corporificavam esse atraso. Entretanto, esse passado parecia resistir e impregnar as novas e desejadas formas de sociabilidade brasileira - modernas, bem frisado.

De diversas maneiras, ao longo da história brasileira, os movimentos populares e de trabalhadores disputaram, mobilizaram e colocaram na cena política tudo aquilo que, segundo uma parte expressiva da literatura 


\section{ReVistg all PaVtg}

\} MOVIMENTOS SOCIAIS E SUBJETIVAÇÃO POLÍTICA - BARROS, J. S. \}

sociológica, seria superado pela modernidade brasileira: a tradição indígena, a tradição dos negros escravizados, a tradição das revoltas populares, suas formas de viver e de se expressar ${ }^{1}$. Essa participação dos "sem-parcela" num processo de debate e planejamento público, justamente em um período de afirmação da democracia representativa e de consolidação da face moderna do Brasil, indaga-nos sobre a nossa própria formação social e os impasses da construção de um projeto nacional.

Em toda discussão social em que há efetivamente algo a discutir é essa estrutura que está implícita, essa estrutura na qual o lugar, o objeto e os sujeitos da discussão estão, eles próprios, em litígio e têm primeiro de ser testados. Antes de qualquer confronto de interesses e de valores, antes de qualquer submissão de afirmações a pedidos de validade entre parceiros constituídos, há o litígio em torno do objeto do litígio, o litígio em torno da existência do litígio e das partes que neles se enfrentam. [...] A afirmação de um mundo comum efetua-se assim numa encenação paradoxal que coloca juntas a comunidade e a não comunidade. (RANCIÈRE, 1996, p. 65-66" grifos nossos).

Afinal, a partir de quais culturas e perspectivas encenamos e constituímos a vida pública brasileira?

\section{Subjetivação política: o fio de uma pesquisa}

Em uma passagem do livro $O$ Desentendimento, Jacques Rancière (1996) expõe sua concepção de política como um processo de subjetivação, mais do que um jogo aritmético de ganhos e perdas. Em suas palavras,

A política é a prática na qual a lógica do traço igualitário assume a forma de tratamento de um dano, onde ela se torna o argumento de um dano principal que vem ligar-se a tal litígio determinado na divisão das ocupações, das funções e dos lugares. Ela existe mediante sujeitos ou dispositivos de subjetivação específicos. [...] A política é assunto de sujeitos, ou melhor, de modos de subjetivação. Por subjetivação vamos entender a produção, por uma série de atos, de uma instância e de uma capacidade de enunciação que não eram identificáveis num campo de experiência dado, cuja identificação portanto caminha

\footnotetext{
${ }^{1}$ Em minha tese de doutoramento (2012), exponho a experiência de participação popular em Belém do Pará, entre os anos de 1997 e 2004, através do OP e depois do Congresso da Cidade. Considero que esta experiência participativa expõe, de maneira contundente, as preocupações aqui tratadas. As diferenças do Congresso da Cidade em relação a outros processos de participação não são uma questão meramente formal: a estrutura do Congresso da Cidade, seu funcionamento, os temas ali tratados e os sujeitos concernidos nesta disputa são, ao mesmo tempo, forma e conteúdo. Essa estrutura (a relação entre forma e conteúdo) nos permite ver aquilo que continuou nublado na consideração da formação brasileira, e permite tomar as nossas "especificidades" como elementos constitutivos e não com distorções a serem superadas. A experiência de Belém nos abre uma perspectiva. A partir dela, podemos interrogar a participação popular no Brasil: considerá-la como experiência que excede os limites da gestão das precariedades justamente porque introduziu e incorporou na gestão das cidades à dimensão utópica, através da participação e do olhar daqueles que historicamente estiveram à margem da vida pública. Este artigo reproduz partes desta tese. (BARROS, 2012).
} 
a par com a reconfiguração do campo da experiência. [...] Toda subjetivação política é uma desidentificação, o arrancar à naturalidade de um lugar, a abertura de um espaço de sujeito onde qualquer um pode contar-se porque é o espaço de uma contagem dos incontados, do relacionamento entre uma parcela e uma ausência de parcela. (RANCIÈRE, 1996, p. 47-48 - grifos no original).

Nesse processo de subjetivação conflituoso e dissensual por definição, o coração da política está justamente no ato de sujeitos encenarem a sua própria condição, produzindo "essas cenas polêmicas, essas cenas paradoxais que revelam a contradição de duas lógicas" (RANCIÈRE, 1996, p. 52), arrancando sua experiência de exploração e desigualdade da naturalidade ou do lugar de esquecimento.

Jacques Rancière (1996) aprofunda a sua concepção de política e, debruçando-se sobre os textos nos quais Aristóteles discute a democracia, ancora aí sua formulação: toda política fundamenta-se na igualdade de "qualquer um com qualquer um"; ou, por outra via, na ausência de uma arkhé que habilite este ou aquele para o exercício do poder. A partir dessa concepção de política, Rancière (1996 e 2005) criticará duramente a república ou outras formas de vida política que pressupõem algum título ou legitimidade anterior para seu exercício. Essa crítica funda-se no fato de a igualdade, em sua acepção, não ser um dado que se aplica à realidade na política, nem mesmo a um objetivo. A igualdade é precisamente a pressuposição da vida política.

Essa pressuposição de uma igualdade contingente permite, através de conflitos e litígios, questionar toda desigualdade que estrutura a vida social. Podemos então argumentar que a política é esta igualdade contingente que aparece sob o nome de liberdade e interrompe a ordem natural da dominação, produzindo um litígio acerca da divisão da sociedade, suas partes e sua contagem.

É desta perspectiva que então retomamos o debate sobre a democracia e as formas de participação popular ali concernidas, tanto em relação à sua própria dinâmica como apontando questões para o conjunto do país.

A democracia é, em geral, o modo de subjetivação da política - se por política entende-se coisa diferente da organização dos corpos em comunidade e gestão dos lugares, poderes e funções. Mais precisamente, democracia é o nome de uma interrupção singular dessa ordem da distribuição dos corpos em comunidade que nos propusemos conceituar sob o conceito ampliado de polícia. É o nome daquilo que vem interromper o bom funcionamento dessa ordem por um dispositivo singular de subjetivação. [...] As formas da democracia são as formas de manifestação dessa aparência, dessa subjetivação não identitária e dessa condução do litígio. (RANCIĖRE, 1996, p. 102-104). 


\section{ReVistg all paUtg}

\} MOVIMENTOS SOCIAIS E SUBJETIVAÇÃO POLITICA - BARROS, J. S. \}

O movimento conflitivo de constituição da cena pública nos interpela e expõe o seu avesso, o "ódio à democracia", o descredenciamento da política tornada gestão, polícia, erosão do sentido de igualdade. Polícia é um termo que Rancière utiliza em oposição à política. Os mecanismos policiais são, para o autor, a forma de disposição de corpos e modos de ser, contrapostos à lógica política da igualdade contingente:

A polícia é assim, antes de mais nada, uma ordem dos corpos que define as divisões entre os modos do fazer, os modos de ser e os modos de dizer, que faz com que tais corpos sejam designados por seu nome para tal lugar e tal tarefa; é uma ordem do visível e do dizível que faz com que esta atividade seja visível e outra não o seja, que essa palavra seja entendida como discurso e outra como ruído. [...] A polícia não é tanto uma 'disciplinarização' dos corpos quanto uma regra de seu aparecer, uma configuração de ocupações e das propriedades dos espaços em que essa ocupações são distribuídas. (RANCIÈRE, 1996, p. 42 - grifos no original).

As duas lógicas (da política e da polícia) se enfrentam; uma como resistência e a outra como potência.

Esta tensão é uma fresta por onde se pode olhar a experiência democrática no Brasil, em diversas formas e aparecimentos fulgurantes, entendida como horizonte e prática política, mas que se desenvolve hoje num cenário de descredenciamento da política. Em tempos de consenso e de anulação da política e da fala, é quase um ato de fé, na expressão de Gramsci (1995, p. 23), perceber pequenos e cotidianos avanços contrários a essa tendência de privatização da vida e enclausuramento.

Jacques Rancière (2005, p. 9-10 - tradução nossa) mobiliza parte de sua teorização sobre a política já desenvolvida, principalmente em $O$ desentendimento, para enfrentar uma nova-velha questão: o ódio à democracia.

O duplo discurso sobre a democracia não é certamente novo. Nós estamos acostumados a ouvir que a democracia era o pior dos governos à exceção de todos os outros. Mas o novo sentimento antidemocrático dá a fórmula uma versão mais perturbadora. O governo democrático, nos dizem, é nefasto/mau quando ele se deixa corromper pela sociedade democrática que quer que todos sejam iguais e todas as diferenças respeitadas. [...] O novo ódio à democracia pode, então, resumir-se em uma tese simples: há somente uma democracia boa, aquela que reprime a catástrofe de uma civilização democrática.

A chave para compreensão desse novo ódio não é a desmontagem de uma armadilha discursiva², ou, como diz o próprio Rancière, "não se

\footnotetext{
${ }^{2}$ Rancière (1996) discute o papel e o significado da ideologia sem negar a herança marxista; muito pelo contrário, como um "leitor refinado de Marx" (a expressão é de Francisco de Oliveira, em seminário de debate do projeto de pesquisa "Hegemonia às a vessas"), ele resgata a elaboração primeira deste acerca da ideologia, afastando-se de leituras que a entendem como simulacro e ilusão.
} 


\section{Revista pll pavtg}

\} MOVIMENTOS SOCIAIS E SUBJETIVAÇÃO POLÍTICA - BARROS, J.S. \}

trata de descobrir uma forma de ideologia contemporânea" (2005, p. 10). Ele aposta que, ao compreender a formação desse ódio, compreenderemos também o "nosso mundo e o que nele tem se entendido por política", além de entender "positivamente o escândalo que pesa sobre a palavra democracia e redescobrir o essencial de sua ideia." (RANCIÈRE, 2005, p. 10 - grifo nosso).

As notícias divulgadas pelos meios de comunicação mundiais e os debates sobre uma suposta vitória da "democracia" no Oriente Médio, com as então recentes eleições no Iraque, são o ponto de partida para Rancière (2005) demonstrar como o deslocamento em torno do que se compreende por democracia não é nem pura ideologia nem autoritarismo disfarçado. Para ele, a operação em andamento é mais sutil: trata-se da construção de uma nova compreensão da democracia, que se ancora na experiência social desta como excesso e necessidade de contenção. Isto se sobrepõe à noção e à experiência de democracia com o reino dos indivíduos e das necessidades ilimitadas ${ }^{3}$.

O argumento central de Rancière (2005), acerca da formação e da experiência contemporânea desse novo ódio, nos remete, portanto, ao deslocamento da noção de democracia, o qual inverte o sentido primeiro e originário desta como contestação de toda desigualdade presente na vida comunitária, que é a própria política. Em outras palavras, esse deslocamento opera a perda do sentido da democracia e da política e assim erode a potência (e o excesso) da igualdade de toda palavra/fala e da própria experiência democrática.

Para discutir o escândalo que a democracia é e provoca, Jacques Rancière (2005) utiliza também a ideia de excesso democrático, que consiste na afirmação de uma igualdade contingente, de "qualquer um com qualquer um", o que possibilita um alargamento real e metafórico da política.

Rancière (2005) identificará um dos pontos fundamentais da torção operada na cena atual para tornar a palavra e a experiência da democracia esvaziada do sentido de igualdade, no interior do debate sobre democracia na França, o qual é profundamente marcado pela ideia de república francesa. É neste sentido que precisa ser apreendida a tensão estabelecida, neste texto, entre democracia e república, que será elaborada a partir da leitura de Rancière sobre $A$ república, de Platão.

Nessa leitura, Rancière discute as concepções platônicas acerca da política, da república e do bom governo, e trata, sobretudo, da oposição deste à democracia; de um lado, para afirmar sua própria noção de de-

\footnotetext{
${ }^{3}$ Em sua tese de doutorado, recentemente publicada, Edson Miagusko (2012) explora essa associação entre democracia e excesso. Para compreender a rejeição ou o descredenciamento das ações públicas dos movimentos de moradia e de sem-teto na Grande São Paulo, assim como suas escolhas políticas, constrói a noção de encolhimento do possível, sendo o excesso a única forma de aparecimento dos "sem-parcela".
} 


\section{ReVistg all paUtg}

\} MOVIMENTOS SOCIAIS E SUBJETIVAÇÃO POLÍTICA - BARROS, J. S. \}

mocracia e seu princípio constitutivo da igualdade e, de outro, para demonstrar como Platão (e, portanto, toda a tradição republicana) mantém nostalgicamente a presença do pastor (ou seja, a não política) no centro de sua noção de política, "de onde serve de referência para desenhar a oposição entre o bom governo e o governo democrático." (2005, p. 41).

Essa presença do pastor no centro da vida política republicana supõe uma desigualdade anterior que aparece como virtude, fundamento da hierarquia que habilita somente alguns para a vida pública e para a política. Essa necessidade de virtudes e habilitações prévias para o exercício do governo, estipulada pelo filósofo grego, é aquilo que hoje, na experiência política, está no centro da associação contemporânea entre democracia e excesso.

Porém, em A República, a despeito dessa desigualdade fundamental pressuposta na enumeração dos títulos para a escolha dos cidadãos aptos ao exercício da política, através do sétimo deles (o sorteio), Platão reintroduz a pura contingência. Esta, segundo Rancière (ano2005), é, a um só tempo, o escandaloso da democracia - o reconhecimento de que inexiste qualquer título (seja de nascimento, antiguidade ou conhecimento) que previamente habilite os homens ao governo - e o coração da política - a igualdade como seu pressuposto e fundamento.

A democracia não é um regime centrado no capricho dos meninos, dos escravos ou dos animais - imagens usadas por Platão para falar da democracia. A democracia é justamente a perda da mensuração da comunidade política dada pela "natureza que emprestava sua lei ao artifício comunitário através de relações de autoridade que estruturam o corpo social." (RANCIÈRE, 2005, p. 48). A democracia é um governo anárquico fundado sobre a ausência de todo título para governar.

Ademais, essa igualdade contingente não é uma ficção. Toda experiência social de desigualdade está permeada por uma experiência rebaixada de igualdade. Está, portanto, pressuposta na desigualdade à medida que, para que os processos de submissão sejam efetivos, as ordenações precisam ser entendidas pelos "desiguais", num processo de legitimação da obediência que supõe a igualdade como base de entendimento entre mandantes e mandados. Essa relação intrincada se revela justamente pelo "escândalo democrático", no qual se aciona a igualdade como contingência questionadora (e desestabilizadora) da experiência social da contagem das parcelas.

Essas pequenas sínteses de afirmações e definições sobre a política desnaturalizam a assimilação da democracia a um sistema de governo ou de representação. Essa desnaturalização implica que a polaridade entre democracia direta e democracia representativa é, no mínimo, uma redução da questão da representação e do poder. O movimento democrático é duplo: alargamento da igualdade do homem público para outros homens, mas também a afirmação de pertencimento de qualquer um à política. 
Dessa constituição do ódio à democracia, interessa reter o cenário que dispõe e nos faz considerar com outros olhos o que está ao nosso redor: se vivemos, nos termos de Rancière (2005), num mundo de des-credenciamento da política e da democracia, o que significa uma experiência democrática recente que aqui retomamos? Até onde podemos supor que essa forma de participação democrática se torna efetiva e nos leva? Ou, antes, seja levada por aqueles que operaram esta encenação política?

Olhar as tentativas de instauração e radicalização da democracia, em suas múltiplas formas e, sobretudo, pelo aparecimento de sujeitos políticos de "atos singulares e precários", abre uma perspectiva de problematização daquilo que reconhecemos como nossa formação social e sociabilidade política brasileira. Ali, reencontramos temas caros e estruturadores da sociabilidade política brasileira: a desigualdade, a impossibilidade de grupos, povos, movimentos, setores inteiros da população brasileira serem "contados", figurando na literatura sobre a formação social brasileira " e, principalmente, na disputa política ", pelo menos desde o final da escravidão e Proclamação da República, como o atraso.

\section{Desigualdade na sociabilidade política brasileira: outra ponta do fio}

É neste sentido que o livro de Maria Sylvia Carvalho Franco (1997 [1 ${ }^{\underline{a}}$ ed. 1969), Homens livres na ordem escravocrata, parece instigante e potente para o debate aqui proposto " embora não haja nenhuma pretensão de esgotá-lo. O interesse por sua leitura reside no fato de que a autora lê a desigualdade como elemento estruturador da política no país. Este é o centro do argumento que aqui pretendo discutir.

Inicialmente escrito como tese de doutoramento, defendida em 1964 na Universidade de São Paulo (USP), sob a orientação de Florestan Fernandes, Homens livres na ordem escravocrata foi publicado pela primeira vez em 1969, pelo Instituto de Estudos Brasileiros da USP. Apesar de ser um estudo que tem como objeto empírico a "velha civilização do café" no século XIX, no Vale do Paraíba, sua atualidade parece residir justamente na capacidade de falar para além de seu recorte geográfico específico; é um estudo rigorosamente sociológico que, partindo de processos-crimes da cidade de Guaratinguetá, compreende e articula três dimensões de análise: a sociedade, o Estado e o mercado, chegando a elaborações que não ficam circunscritas à dimensão local ou comunitária.

O interesse inicial pela tese de Maria Sylvia (1997) reside na compreensão que pode ser apreendida de sua leitura, de nossa formação social não como uma incompletude ou como uma sociedade moderna que guarda traços atrasados ou arcaicos, entraves para seu desenvolvimento. É a própria autora que argumenta em favor de um tipo de leitura menos estanque 


\title{
hevistg all paUtg
}

\} MOVIMENTOS SOCIAIS E SUBJETIVAÇÃO POLÍTICA - BARROS, J. S. \}

desses "traços", supostamente de atraso, no conjunto do desenvolvimento brasileiro:

\begin{abstract}
pretendi também esclarecer como no interior mesmo da sociedade brasileira aspectos 'tradicionais' sofreram uma redefinição de sentido ao dar-se o deslanche da produção mercantil, mantendo-se constante a sua forma. nesses termos, o que se observa é uma continuidade do 'velho' para o 'novo', uma rapidez nas transformações, em lugar das 'resistências a mudança' que em geral se aponta. Levando adiante essa linha de observação, procurei esclarecer como o conjunto de elementos que formalmente poderiam ser identificados como tradicionais apenas se torna legível quando referido à produção lucrativa. (FRANCO, 1997, p. 18 - grifos no original).
\end{abstract}

Neste sentido, é possível afirmar que Franco (1997) se afasta da tradição de pensamento que compreende o Brasil e sua formação social tanto como incompletude, como é possível ler nos textos de Oliveira Vianna (1987) ou ainda de Sérgio Buarque (1985), quanto na chave dual e dicotômica.

Werneck Vianna (1999) discute a recepção de Weber no Brasil, identificando duas leituras opostas do processo de modernização brasileiro na perspectiva do atraso: de um lado, Raymundo Faoro e Simon Schwartzman, de outro, Florestan Fernandes e Maria Sylvia de Carvalho Franco. Faoro e Schwartzman, ao considerarem o "patrimonialismo como um fenômeno do Estado" (WERNECK VIANNA, 1999, p. 38), identificam o atraso com a instância do político e perdem de vista as relações societais que se estabelecem entre atraso e moderno, lidos nesta perspectiva como oposição e não como combinação. No outro polo da recepção weberiana, Maria Sylvia e Florestan compreenderiam essas mesmas relações entre atrasomoderno, no quadro do desenvolvimento do capitalismo no país, não "em contraposição agonística", mas de forma combinada. O Estado patrimonialista, nessa perspectiva, não é lido como um ente a priori, imposto à sociedade no Brasil, mas como resultado das relações que se desenvolvem naquele tecido social. O atraso e o moderno são, assim, analisados desde o ponto de vista da sociedade, interrogando essa imbricação e como ele se condensa no Estado.

Vale a pena seguir um pouco a argumentação de Werneck (1999) sobre Maria Sylvia e Florestan para constatar que o autor sustenta que, das leituras destes, depreendemos a permanência do atraso, representado pelas oligarquias agrárias incrustadas no Estado, no seio de uma modernização fomentada por "novas elites" industriais e urbanas. Gostaria de chamar atenção para que, na leitura detalhada e profunda do texto de Franco (1997), Werneck Vianna (1999) identifica, na dominação pessoal, o elemento significativo e fundamental para a permanência do atraso no âmbito da sociedade brasileira em formação. 


\section{Revigta all paעtg}

\} MOVIMENTOS SOCIAIS E SUBJETIVAÇÃO POLÍTICA - BARROS, J. S. \}

Dois aspectos tratados de forma condensada na introdução de Franco (1997) são importantes para compreensão da figuração da formação social brasileira que emerge dele, a saber: a tese sustentada sobre escravidão e a relação entre "produção direta dos meios de vida" (economia de subsistência) e "produção de mercadorias" (produção mercantil), compreendida como unidade contraditória (FRANCO, 1997).

Esses dois aspectos autorizam a leitura do processo de formação social do Brasil como um processo não disjuntivo, que rompe com a percepção de uma formação social dual, especialmente no que diz respeito à relação entre Estado e sociedade.

Como o título do livro já anuncia, a autora não trata abertamente dos escravos e nem da escravidão, mas sim concentra sua análise nos homens livres e pobres que "não conheceram os rigores do trabalho forçado e não se proletarizaram" (FRANCO, 1997, p. 14), mas que conheceram profundamente a violência e a desigualdade, constituindo-se como uma "ralé". A caracterização dos homens livres e pobres afasta-os da noção de dispensabilidade absoluta, ainda que não sejam ou estejam no centro da economia de mercado. A compreensão de seu lugar é feita na tensão marginalidade constitutiva - aproveitamento residual.

O que está em questão em Franco (1997) não é o enigma de uma formação social cujo suposto truncamento deveria ser tomado como especificidade ou como impeditivo na tarefa de superação do atraso em direção a uma sociedade moderna e democrática. Seu foco parece ser a compreensão das tensões e diferenças que dão corpo à nossa especificidade, arranjam-se e combinam-se numa formação social concreta e como esta se articula com o sistema econômico no qual o Brasil está inserido - afastandose, assim, de uma "sociologia da inautencidade" (SOUZA, 2000).

Na Introdução de Homens livres na ordem escravocrata, Franco (1997, p. 17) anuncia a tese central do livro: a violência que "aparecia por toda a parte" nos processos-crimes consultados mostrava-se como elemento constitutivo das relações e não somente nas situações de crime especificamente.

Concentrando-se no estudo sobre os homens livres e pobres nessa sociedade, Maria Sylvia (1997) mostra como a violência nas relações mais cotidianas estruturam a vida e a própria experiência de mundo que aqueles homens tiveram, situando-a para além de uma forma de regulação comunitária em períodos de crise ou em situações de defesa pela sobrevivência. De outra maneira, pelo lugar lateral que ocuparam na produção, pela precariedade e penúria na qual viviam, esses homens experimentaram a constituição de si marcados por uma forte experiência subjetiva, sem a constituição de um "mundo exterior" que pudesse conduzir as relações com o outro. "Em seu mundo vazio de coisas e falta de regulamentação" (FRANCO, 1997, p. 62), a violência então se constitui como componente estrutural da e na relação com o mundo e com os homens, no sentido de 


\section{ReVistg all PaVtg}

\} MOVIMENTOS SOCIAIS E SUBJETIVAÇÃO POLÍTICA - BARROS, J. S. \}

que se torna sua única forma de experimentar a vida no mundo, através de sua coragem e valentia.

Há uma novidade no tratamento da violência e da desigualdade na tese de Maria Sylvia (1997), especialmente se considerarmos os autores de extração conservadora do pensamento brasileiro. A violência, que não deveria ser uma surpresa em processos-crimes, como a autora nos adverte, é tratada como um elemento analítico que abre a possibilidade de leitura da própria sociedade na qual aparece. A análise da violência empreendida pela autora extrapola os limites de uma sociologia da violência ou, ainda, permite uma leitura do Brasil a partir de sua história social num determinado momento, mas numa perspectiva de compreensão de sua formação social e suas mediações.

A violência que emerge do material de campo coletado não é tomada como desvio em situações de quebra da normalidade das relações; é tratada no bojo das situações concretas nas quais aparece, revelando mais do que tensões momentâneas no contexto de uma comunidade autorregulada. Essa perspectiva assumida pela autora parece-me só ser possível no conjunto de sua orientação geral de compreensão da sociedade brasileira por um viés positivo e não dicotômico.

A análise da dominação pessoal empreendida por Franco (1997) concentra-se em três tipos sociais diferentes: os tropeiros e vendeiros, os sitiantes e os agregados e camaradas. A figura do homem livre e pobre será projetada no sistema social, vinculando-o ao conjunto do sistema social no qual está inserido.

A organização do sistema de produção cafeeira que comportava, nas suas franjas, "serviços residuais, que na maior parte não poderiam ser feitos por escravos e não interessavam aos homens de patrimônio" (FRANCO, 1997, p. 65), significou a possibilidade de alguma integração desses homens através de oportunidades de trabalho livre, não assalariado, nos marcos formais das relações de mercado. Essa inserção lateral ou residual, para usar os termos da autora, marca o "lugar sem-lugar" que estes tipos ocuparam, junto com outros aspectos: uma inserção que comporta, de fato, um lugar diferenciado em relação aos caipiras, de modo geral, e algum grau de autonomia em relação aos senhores de terra, mas que reproduz formas de dominação e desigualdade em muitas dimensões.

As relações entre os tropeiros e os proprietários de terras cafeicultores davam-se basicamente em função do transporte da carga do café e abastecimento das fazendas em lombo de burros e situava-se na imbricação entre a tecnologia rudimentar referida, a economia de subsistência e o grande empreendimento mercantil e suas operações comerciais. Lugar paradigmático onde a superfluidade dos homens pobres e livres é, em certa medida, contestada. Contudo, em seguida reafirmada.

Algo aparentemente contraditório, dada a natureza da relação de mercado que se estabelece, mas que nos dá a chave para acessar a for- 


\section{Revista pll paעtg}

\} MOVIMENTOS SOCIAIS E SUBJETIVAÇÃO POLÍTICA - BARROS, J. S. \}

ma como se conjugam liberalismo e dominação no Brasil. A dependência do tropeiro em relação ao proprietário fazia-se presente na cessão de terras para criação de rebanho ou de alojamento para os seus durante o transporte, obrigando o tropeiro a retribuir os benefícios recebidos. Dessa maneira, uma linha de dependência "tênue, mas forte" matiza a suposta liberdade e igualdade na relação mercantil com os proprietários, e dá sentido à advertência que a autora faz em relação ao conceito de liberdade:

Assim, esse conceito de liberdade só poderá ter seu conteúdo precisado à luz do regime de propriedade, apreendido não apenas através de sua expressão codificada, que prescreve direitos 'formais', mas sobretudo através das condições que regulam a distribuição efetiva do poder, desvendando-se assim os limites dos direitos 'vividos'. Em resumo, o conceito genérico de liberdade implícito nas relações de mercado, que é afirmado no princípio da propriedade privada, só poderá alcançar teor explicativo quando nuançado em função do sistema de dominação a que se conjuga. (FRANÇO, 1997, p. 68).

O que matiza esse conceito liberal de liberdade é justamente a violência constitutiva que as condições concretas de vida engendram neste país: relações que partem do pressuposto da desigualdade fundante de todo o código de sociabilidade.

Observamos esse mesmo princípio de desigualdade na relação entre vendeiros e proprietários, ou ainda entre estes e os sitiantes e camaradas. Os vendeiros, na sua posição ambígua ou "oscilante", viviam entre os dois polos, estabelecendo relação tanto com os estratos superiores quanto com os inferiores. Permitida pelo sitiante, essa aproximação com os/dos escravos e inferiores desqualifica-o aos olhos dos proprietários e engendra sua reprovação.

É preciso, ainda, atentar para o fato de que o vendeiro condensa em si uma atividade "marginal e quase dispensável" entre uma economia de mercado e uma de subsistência no seio de uma vida comunitária (FRANCO, 1997, p. 80). Também a violência está presente, inscrita na moralidade, "gerada pela ordem social e como negadora dessa mesma ordem." (FRANCO, 1997, p. 84).

São as relações de compadrio entre sitiantes e fazendeiros que ajudam a revelar um traço importante da forma como a violência e a desigualdade se imbricam e engendram nossa formação social: uma aparência de nivelamento social ou de inexistência de clivagens e diferenciações sociais, mas também um profundo apartamento entre os sujeitos, menos pelas suas relações concretas e mais por aquilo que rege e estrutura essa relação. Os laços de compadrio encerram claramente uma dimensão de dominação, estabelecendo uma rede de dívidas e obrigações. Entretanto, guardam uma dimensão de equivalência entre as partes - daí o suposto nivelamento de posições hierárquicas. 


\section{hevistg all paUtg}

\} MOVIMENTOS SOCIAIS E SUBJETIVAÇÃO POLÍTICA - BARROS, J. S. \}

É justamente essa tensão que explica ou explicita as formas (estas, sim, estáveis) de dominação política: o reconhecimento social cotidiano dos homens livres como pessoas negava a própria humanidade deles, uma vez que os encapsulava numa teia de obrigações e favores. Desta forma, eram compelidos a "comportamentos automáticos, de onde o critério, o arbítrio e o juízo estavam completamente excluídos." (FRANCO, 1997, p. 93). Ou seja, base de sustentação para a perenidade da dominação política dos fazendeiros e a filiação política dos sitiantes a eles.

Esta parece ser a questão central de Franco (1997) para compreensão da formação social brasileira: a articulação entre violência e desigualdade como padrão de sociabilidade política. A dominação pessoal emerge, assim, como código estruturador na formação social brasileira.

Entretanto, gostaria de propor um deslocamento dessa perspectiva: por detrás das formas concretas de dominação descritas e analisadas por Franco (1997), há uma articulação, nos moldes de uma unidade contraditória, entre os pressupostos sobre os quais se constituem as relações entres esses grupos sociais diferentes. Ou seja, entre igualdade e sua negação: a desigualdade. Em certa medida, a dominação pessoal seria mais o resultado que essa articulação igualdade-desigualdade estrutura e menos o seu pressuposto.

Não significa dizer, no entanto, que a dominação pessoal não opere ou que deva ser considerada menor em relação ao seu mecanismo fundante. Argumento que a dominação pessoal opera no duplo mecanismo de coerção e convencimento. É justamente no polo do convencimento ou do consenso, para utilizar uma noção cara a Rancière (1996) - a desigualdade ou a negação da igualdade política - que está o mecanismo mais poderoso de legitimação social das formas subalternas de relação entre os homens livres e pobres e as camadas dominantes.

Esse deslocamento de perspectiva permite iluminar as tentativas de rompimento desta ordem de coisas ao longo da história recente do país. É a desigualdade na sua acepção política nos termos de Rancière, como vimos acima, que funda a dominação. Ela é reiterada muitas e vezes não só na relação estrita de homens livres e proprietários de terras, mas se espraia para o conjunto das relações sociais nas diversas dimensões (sociedade, Estado e mercado) como padrão de sociabilidade, não necessariamente sob a forma da dominação pessoal descrita por Franco (1997).

Gostaria de argumentar em favor desse deslocamento sinalizando também que, ao tratar diretamente da escravidão, a presença ausente, a autora retoma a figuração dos escravos como não humanos. Dessa maneira, mostra como, entre os homens livres e os escravos - guardadas as diferenças -, há algo que funda as duas formas de dominação e violência: a desigualdade sobre a qual se assenta uma e outra e a negação da humanidade de ambos - os escravos diretamente como coisa e os homens livres através da construção de uma criatura domesticada. 


\section{Revista pll paעtg}

\} MOVIMENTOS SOCIAIS E SUBJETIVAÇÃO POLÍTICA - BARROS, J. S. \}

leitura.

Reproduzo abaixo o longo trecho que, acredito, autoriza essa

Essas considerações mostram o quanto esse tipo de dominação pode exterminar a vontade do homem a ele submetido e reduzi-lo à inércia. Na propriedade servil, embora o escravo seja transformado em coisa e a extinção de sua consciência vá ao limite da autonegação como pessoa, existem marcas violentas que denunciam a opressão que sobre ele pesa e nessa medida possibilitam pelo menos um 'vago desejo de liberdade', 'uma mera necessidade subjetiva de afirmação que não encontra condição de realizar-se concretamente' [Cardoso, 1962, cap. III]. Liberdade impossível mas pelo menos desejada, o que devolve ao escravo, embora apenas como projeção individual, um sentido de humanidade. Para aquele que se encontra submetido ao domínio pessoal, inexistem marcas objetivadas do seu sistema de constrições a que a sua existência está confinada: seu mundo é formalmente livre. Não é possível a descoberta de que sua vontade está presa a do seu superior, pois o processo de sujeição tem lugar como se fosse natural e espontâneo. Anulam-se as possibilidades de autoconsciência, visto como dissolvem na vida social todas as referências a partir das quais ela poderia se constituir. Plenamente desenvolvida, a dominação pessoal transforma aquele que a sofre numa criatura domesticada: proteção e benevolência Ihe são concedidas em troca de fidelidade e serviços reflexos. Assim, para aquele que está preso ao poder pessoal se define um destino imóvel, que se fecha insensivelmente no conformismo. (FRANCO, 1997, p. 95 grifos no original).

Vale ainda sublinhar que, na sua caracterização sobre os agregados e camaradas, e mesmo entre os vendeiros e sitiantes, Franco (1997) identifica formas e mecanismos de rompimento com a ordem de dominação. Entretanto, essas saídas são unicamente pessoais:

diante deles [do vendeiro, do tropeiro ou do pequeno proprietário] estavam dados os meios para enriquecer e ascender socialmente numa formação econômica em que progressivamente se determinavam e se cristalizavam as diferenças de fortuna e destino." (FRANCO, 1997, p. 111).

Note-se que essa saída pelo enriquecimento via mercado ancorase no mesmo suporte que a educação: a possibilidade de ascensão pela posse ou pela educação; ascensão que significa "ser alguém", uma vez que o sistema de regulação formal não garante, através de direitos ou instituições públicas, essa possibilidade de reconhecimento do estatuto de igualdade e apenas fragilmente de sua mobilidade social.

A desigualdade não se encerra com a abolição da escravidão nem mesmo com a constituição de relações de mercado e assalariamento do trabalho. A "presença ausente" da escravidão aqui é reencontrada como uma presença mesmo. Ou, de outra forma, ao tratar da constituição de re- 


\section{hevistg all paUtg}

\} MOVIMENTOS SOCIAIS E SUBJETIVAÇÃO POLÍTICA - BARROS, J. S. \}

lações de trabalho mercantis e da consolidação da produção capitalista, as marcas da escravidão aparecem e ressurgem no dito trabalho livre.

Chamo a atenção sobre a integridade desse conjunto feito de moderação e excesso, que esteve presente no tratamento do senhor ao seu escravo, não tanto para iluminar esta relação, que não é objeto deste trabalho, mas para acentuar a referência dos processos socioeconômicos em curso dentro da fazenda ao modo de sua organização, que articulou produção mercantil e produção direta de meios de vida.

Essa referência da escravidão à estrutura global da fazenda encaminha, de maneira correta, o entendimento de um tema que é central neste estudo e que não pode ser tratado independentemente daquela instituição. Refiro-me ao trabalho, como atividade que atravessou de ponta a ponta a sociedade e impôs-se como requisito mesmo para as classes dominantes. [...] E, reafirmo, tratar-se de uma sociedade escravocrata, em que forçosamente o princípio da separação nítida entre o requisito do trabalho e o privilégio de sua dispensa se fazia fundamental para a própria afirmação do poder. É fora de dúvida que essa amálgama de escravidão e produção mercantil, gerida e controlada diretamente pelas camadas privilegiadas, seguiu cheia de ambiguidades e tensões e o ajustamento entre dominados e dominantes definiu-se de maneira complexa no processo de produção. (FRANCO, 1997, p. 212-213 - grifo no original).

A desigualdade persiste, nesse sentido, como pressuposto, e não somente como efeito da formação social brasileira.

\section{Um fio, duas pontas e o nó}

Atraso e pobreza: uma persistência nas leituras da formação social brasileira. É certo que a pobreza e o atraso flagrados no final do século XIX e começo do XX são muito diferentes da pobreza e das desigualdades sociais contemporâneas. Contudo, essa transformação (comprovada à exaustão pelos levantamentos socioeconômicos que indicam crescimento econômico e melhora das condições de vida da população, mas que não explicita o recrudescimento da concentração de renda, por exemplo) revela mais do que a transformação de um país agrário, recém constituído e emancipado em um país que se urbanizou e se industrializou, que promulgou direitos sociais e espaços de participação social. Enfim, uma sociedade que, apesar da pobreza "persistente", fez-se moderna.

A persistência incômoda desse atraso e dessa pobreza (ou seria a presença incômoda dos atrasados e dos pobres?) revela a forma específica como esta sociedade articulou mecanismos estritamente modernos aos nomeados como atrasados. A formulação de Francisco de Oliveira (1972, p. 


\section{Revigta all paעtg}

\} MOVIMENTOS SOCIAIS E SUBJETIVAÇÃO POLÍTICA - BARROS, J. S. \}

28 " grifos no original) é a que mais precisamente desvenda essa combinação de atraso e moderno:

O processo descrito, em vários níveis e formas, constitui o modo de acumulação global próprio da expansão do capitalismo no Brasil pós-anos 1930. A evidente desigualdade de que se reveste que, para usar a expressão famosa de Trotsky, é não somente desigual mas combinada, é produto antes de uma base capitalística de acumulação razoavelmente pobre para sustentar a expansão industrial e a conversão da economia pós-anos 1930, que da existência de setores 'atrasado' e 'moderno'. Essa combinação de desigualdades não é original; em qualquer câmbio de sistemas ou de ciclos, ela é, antes, uma presença constante. A originalidade consistiria talvez em dizer que - sem abusar do gosto pelo paradoxo - a expansão do capitalismo no Brasil se dá introduzindo relações novas no arcaico e reproduzindo relações arcaicas no novo, um modo de compatibilizar a acumulação global, em que a introdução das relações novas no arcaico libera força de trabalho que suporta a acumulação industrial-urbana e em que a reprodução de relações arcaicas no novo preserva o potencial de acumulação liberado exclusivamente para fins de expansão do próprio novo.

\section{bicho ornitorrinco:}

Atualizada, foi figurada como o esquisito, mas existente e vivo,

O ornitorrinco é uma das sociedades capitalistas mais desigualitárias - mais até que as economias mais pobres da África que, a rigor, não podem ser tomadas como economias capitalistas -, apesar de ter experimentado as taxas de crescimento mais expressivas em período longo; sou tentado a dizer com a elegância francesa, et pour cause. As determinações mais evidentes dessa contradição residem na combinação do estatuto rebaixado da força de trabalho com dependência externa. A primeira sustentou uma forma de acumulação que financiou a expansão, isto é, o subdesenvolvimento, conforme interpretado neste [na] Crítica à razão dualista, mas combinando-se com a segunda produziu um mercado interno apto apenas a consumir cópias dando como resultado uma reiteração não virtuosa. (OLIVEIRA, 2003, p. 143).

Em certa medida, essa leitura autoriza uma percepção do país não mais como incompletude. Portanto, o atraso não é uma pedra a ser retirada do caminho, assim com a pobreza não será incorporada ou redimida pelo desenvolvimento e suposto espraiamento dos direitos. Não se trata de um mecanismo truncado. As arestas do processo "o atraso e, portanto, aqueles que carregam as suas marcas, que se interpõem ao desenvolvimento (o que quer que isto queira dizer) ou os pobres ainda não beneficiados por suas benesses - não são resquícios de um tempo pré-capitalista; são rigorosamente seus produtos, como demonstraram Francisco de Oliveira $(1972,2003)$ e, por outro caminho, Maria Sylvia (1997). Os pobres, figurados 


\section{ReVistg all paUtg}

\} MOVIMENTOS SOCIAIS E SUBJETIVAÇÃO POLÍTICA - BARROS, J. S. \}

como o atraso ou o arcaísmo, são assim invisibilizados. Está tudo em seu lugar.

A pobreza documentada e apontada ao longo da história brasileira só pôde sair deste lugar de natureza, deslocada do pertencimento da vida política do país, através do esforço desses "pobres e atrasados" que, figurando-se como trabalhadores, interpuseram-se às formas de dominação e exigiram direitos - de formas diversas, ao longo dos mais de cento e vinte anos da história recente do Brasil; isto para nos ater ao período de instituição do trabalho livre como o centro da dinâmica econômica.

Mais recentemente, o seu aparecimento como questão social nos anos 1980 é fruto das lutas que articularam a reivindicação da liberdade política ante à Ditadura Militar, instaurada com o Golpe de 1964, com a reivindicação de justiça social, a partir da noção dos direitos sociais e a construção de políticas públicas universais e com forte acento participativo. Essa politização da pobreza e a aposta que esta supunha, foi pega no contrapé por medidas de ajuste econômico que caracterizaram os anos 1990, e o desmanche do ainda nascente corpo regulatório das políticas sociais ancoradas na Constituinte Cidadã de 1988.

Esta conexão - naturalizada - entre atraso e pobreza, tantas e muitas vezes reiteradas nas leituras sobre a formação social brasileira, é nó do enigma. Uma vez desfeito, expõe a desigualdade política ou a negação da igualdade contingente que lhe constitui. Este só se pode desfazer à medida que o processo de subjetivação política se imponha e desfaça a organização de corpos e falas no espaço social brasileiro.

Essa impossibilidade de igualdade, ou seja, a concretude da desigualdade, é o centro da contestação ao qual se dirige a reparação do dano. A entrada de mulheres e homens não contados na cena política expõe e questiona justamente essa sobreposição entre atraso e pobreza e a conexão imediata entre atraso e o povo. Essa pobreza desencarnada, tornada natureza, justamente permite a figuração do povo como portador deste atraso. Afinal, são estes que se põem em pé e se constituem como sujeitos nos processos de participação política.

nó.

É uma fresta por onde se pode ver - e apostar - em desarmar este 


\section{Revigta all paעtg}

\} MOVIMENTOS SOCIAIS E SUBJETIVAÇÃO POLÍTICA - BARROS, J. S. \}

\section{Referências}

BAIERLE, S. "A explosão da experiência: emergência de um novo princípio ético-político nos movimentos populares urbanos em Porto Alegre". In: ALVAREZ, S.E.; DAGNINO, E.; ESCOBAR, A. (Org.). Cultura e política nos movimentos sociais latino-americanos. Belo Horizonte: Ed. da UFMG, 2000.

BARROS, J.S. Participação popular em Belém: a experiência do Congresso da Cidade e do Orçamento Participativo e a sociabilidade política brasileira. Tese (Doutorado) - Curso de Sociologia da FFLCH-USP. São Paulo. 2012).

DAGNINO, E. (Org.). Anos 90: sociedade e política no Brasil. São Paulo: Brasiliense. 1994.

Terra. 2002.

. Sociedade civil e espaços públicos no Brasil. São Paulo: Paz e

FERNANDES, F. A revolução burguesa no Brasil. Rio de Janeiro: Editora Guanabara. 1987.

FRANCO, M.S.C. Homens livres na ordem escravocrata. São Paulo: Ed. da Unesp. 1997.

HOLANDA, S.B. Raízes do Brasil. São Paulo: Companhia das Letras. 1995. GRAMSCI, A. Concepção dialética da história. Rio de Janeiro: Civilização Brasileira. 1995.

MIAGUSKO, E. Greve dos petroleiros de 1995: a construção democrática em questão. Dissertação (Mestrado) "Programa de Pós-Graduação em Sociologia da USP. São Paulo. 2001 (mimeo).

- Movimentos de moradia e sem-teto em São Paulo. São Paulo:

Alameda. 2012.

OLIVEIRA, F. Economia brasileira: crítica a razão dualista. Estudos CEBRAP, 1972 , n. 2, p. 3-82.

. Crítica à razão dualista: o ornitorrinco. São Paulo: Boitempo. 2003.

PAOLI, M.C. Os trabalhadores urbanos na fala dos outros. In: LOPES, J.S.L. (Coord.). Cultura e identidade operária. Rio de Janeiro: Marco Zero/Ed. da UFRJ. 1987.

; SADER, E. Sobre "classes populares" no pensamento sociológico brasileiro. In: CARDOSO, R. (Org.). A aventura antropológica. Rio de Janeiro: Editora Paz e Terra. 1986.

RANCIÈRE, J. O desentendimento. São Paulo: Editora 34. 1996.

. La haine de la démocratie. Paris: La Fabrique. 2005.

SADER, E. Quando novos personagens entram em cena. Rio de Janeiro: Paz e Terra. 1988. 


\section{heVista pll paעtg}

\} MOVIMENTOS SOCIAIS E SUBJETIVAÇÃO POLÍTICA - BARROS, J. S. \}

SCHWARZ, R. Sequências brasileiras. São Paulo: Companhia das Letras. 1999.

SOUZA, J. A modernização seletiva: uma reinterpretação do dilema brasileiro. Brasília: Editora Universidade de Brasília. 2000.

TELLES, V.S. Pobreza e cidadania: figurações da questão social no Brasil moderno. In: Direitos Sociais: afinal de que se trata? Belo Horizonte: Ed. da UFMG. 1999.

. Pobreza e cidadania. São Paulo: Editora 34/ Edusp. 2001.

WERNECK VIANNA, L. Weber e a interpretação do Brasil. Novos Estudos CEBRAP, n. 53. 1999.

Recebido em 17 de novembro de 2014.

Aprovado para publicação em 08 de dezembro de 2014. 